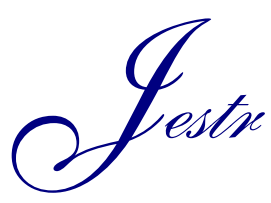

\title{
The Effect of Pile Cross Section on the Lateral behavior of Piles Under Combined Loading
}

\author{
Jasim M. Abbas* and Qasim Ibrahim Hussain \\ Department of Civil Engineering, College of Engineering, Diyala University, Iraq
}

Received 17 January 2018; Accepted 19 July 2018

\begin{abstract}
In the present study, the effect of pile cross section on the lateral behavior of pile when subjected to combined loads has been investigated. The lateral tip displacement, as well as the deformation along the pile depth, has been taken into account. To achieve the objective that obtains from this work, the laboratory work was developed, which included piles made from aluminum and steel materials with circular and square cross-sections for each one. The diameter and the corresponding width of a square section of the used piles were $15 \mathrm{~mm}$, with a slenderness ratio (L/D) of (25 and 45) and embedded in sandy soil with a relative density (Dr) of $70 \%$. The test results revealed that the pile with square cross section was more resistance to lateral load compared with the traditional shape, with improvement in the range of (30$65 \%$ ) in different condition. Also, the presence of axial load effect on the lateral response of piles.
\end{abstract}

Keywords: piles, cross section, pile deformation, slenderness ratio, combined loading, relative density.

\section{Introduction}

Piles can be defined as a structural element that transferred the superstructure loads to the strong soil layer in case of presence of weak soil in site or high external loads from the superstructure. The pile foundation carries both axial and lateral load in the same time when subjected to external loading from the superstructure (Abbas et. al. 2010).

Many previous works were taken into account the effect of only pure lateral load on the piles such as Bouafia 2007, Abbas et al. 2008, Ozden and Akdag 2009, Rahman et al. 2009, Fatahi et al. 2014; Abdrabbo and El-Wakil 2016, Yan et al. 2016 and others. While in fact, the pile was subjected to both axial and lateral loads at the same time, and this case should be taken into consideration in the analysis of lateral pile behavior. According to Lee at all. 2011, the limited research on this topic produced conflicting results concerning the effect of axial load on the lateral response of pile. According to the authors, these limited studies were not covered most of the pile foundation conditions that usually influence on the lateral pile performance under such loading condition, such as pile cross section, pile slenderness ratio, and soil density, especially by using laboratory program. The number of limited studies, including the pile performance under combined loading such as Karthigeyan et al. 2006\&2007, Rajagopal and Karthigeyan 2008, Abbas et al. 2010, 2015 and 2017.

In the present study, the effect of pile cross sections on the behavior of it under combined loads was investigated with into consideration some parameters like: the values of combined load, the slenderness ratios of the pile, and pile materials.

*E-mail address: prabhusrm2015@gmail.com

ISSN: $1791-2377$ @ 2018 Eastern Macedonia and Thrace Institute of Technology. All rights reserved.

doi:10.25103/jestr.113.24

\section{Experimental work}

\subsection{Soil Type}

The soil used in the present study was brought from Karbala governorate, Iraq. The laboratory tests based on ASTM specifications were conducted on it to explain its properties. Table 1 lists the results of the laboratory tests of soil. In eve analysis was shown in figure 1

Table 1. The physical properties of the used soil

\begin{tabular}{c|c}
\hline Physical properties & Amount \\
\hline $\mathbf{D}_{\mathbf{5 0}}$ & 0.45 \\
$\mathbf{D}_{\mathbf{1 0}}$ & 0.191 \\
$\mathbf{D}_{\mathbf{3 0}}$ & 0.32 \\
$\mathbf{D}_{\mathbf{6 0}}$ & 0.55 \\
Coefficient of uniformity, $\boldsymbol{C}_{\boldsymbol{U}}$ & 2.88 \\
Coefficient of curvature, $\boldsymbol{C}_{\boldsymbol{C}}$ & 0.98 \\
Classification based on & $\mathrm{SP}$ \\
$\boldsymbol{U} \boldsymbol{S} \boldsymbol{S}$ & \\
Specific gravity, $\boldsymbol{G}_{\boldsymbol{S}}$ & 2.67 \\
Dry unit weight, $\boldsymbol{\gamma}_{d}\left(\mathrm{kN} / \mathrm{m}^{3}\right)$ & 16.48 \\
Angle of internal friction, $\boldsymbol{\varnothing}$ & 39.28 \\
\hline
\end{tabular}

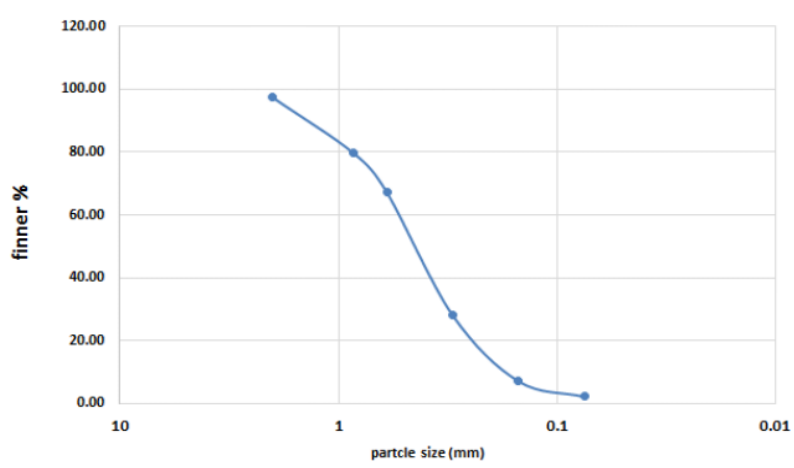

Fig. 1. The grain size distribution of the used soil 


\subsection{Piles}

The piles adopted in this study were made from aluminum and steel materials with circular and square sections with diameter and the side length of square section limited to $15 \mathrm{~mm}$ and slenderness ratio of pile $\mathrm{L} / \mathrm{D}$ or $\mathrm{L} / \mathrm{B}$ of 25 and 45 .

\subsection{Laboratory Model}

The laboratory model used in the present study was manufactured and made from steel plate with $4 \mathrm{~mm}$ thickness with dimensions of $(1000 \times 1000 \times 1000) \mathrm{mm}$ to prevent the effect of the interface between the stress of the pile and tank walls which effect on the test results. The frame of the model contained on the raining system which consists of the sliding system along the container via 4 wheels and hopper which connected to that the sliding system for the purpose of soil deposit preparation. Figure 2 shows the adopted model

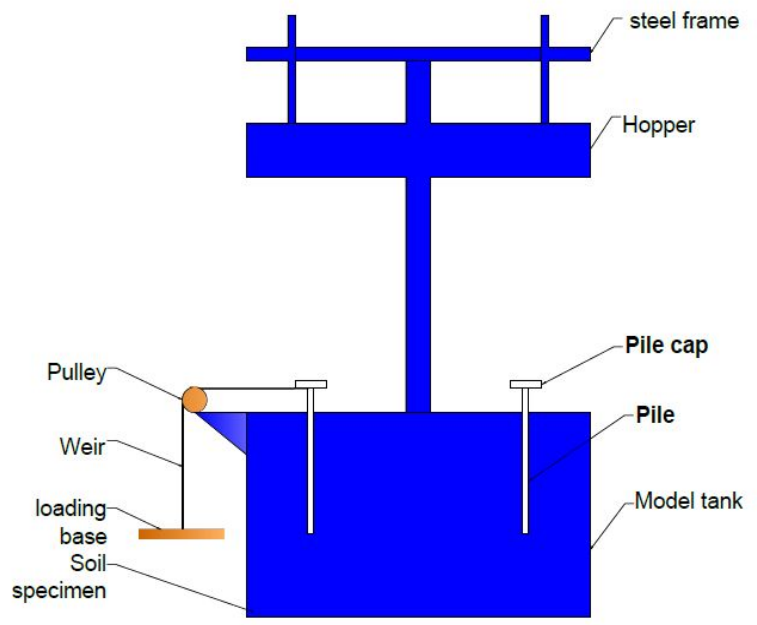

Fig. 2. The laboratory model used in this study

\subsection{Strain Gauges}

The lateral strain occurs along the shaft of piles inside the soil deposit is measured by gluing four TML Japan electrical strain gauges. Two types of strain gauges were used based on the pile materials, type (FLA-5-23) with gauge factor (2.16) was used for aluminum piles and type (FLA-5-11-3L) with gauge factor (2.13) for steel piles. Both these types have dimensions of $(5 \times 10) \mathrm{mm}$ and resistance of $(120 \Omega)$ and fixed on the distance of $(0.25 \mathrm{~L}, 0.5 \mathrm{~L}, 0.75 \mathrm{~L}, \mathrm{~L}-5 \mathrm{~cm})$ from the pile tip. Figure 3, explain the location of the strain gauges after fixed it on the pile side. The strain gauges were fixed at the side of piles in the very accurate form by using a special type of glue and after that, the strain gauges were covered with paste and adhesive tape to prevent it from any damages during the tests.

\subsection{Soil Preparation}

The raining technique was used to pour the sand deposit in the model tank to reach up to the required density. The hopper was made from steel with $(4 \mathrm{~mm})$ thickness and has the dimensions of $(200 \times 200 \times 800) \mathrm{mm}$, and has two opening strips of $(10 \mathrm{~mm})$ to rain the sand inside the soil tank. By using two adjustable shafts, the hopper connected to the sliding beam found in the raining system, these adjustable shafts enable from control the height of hopper to obtain on the required height of fall for raining the sand. The sliding beam enables the hopper from move in horizontal form by four rollers sliding on the raining frame.

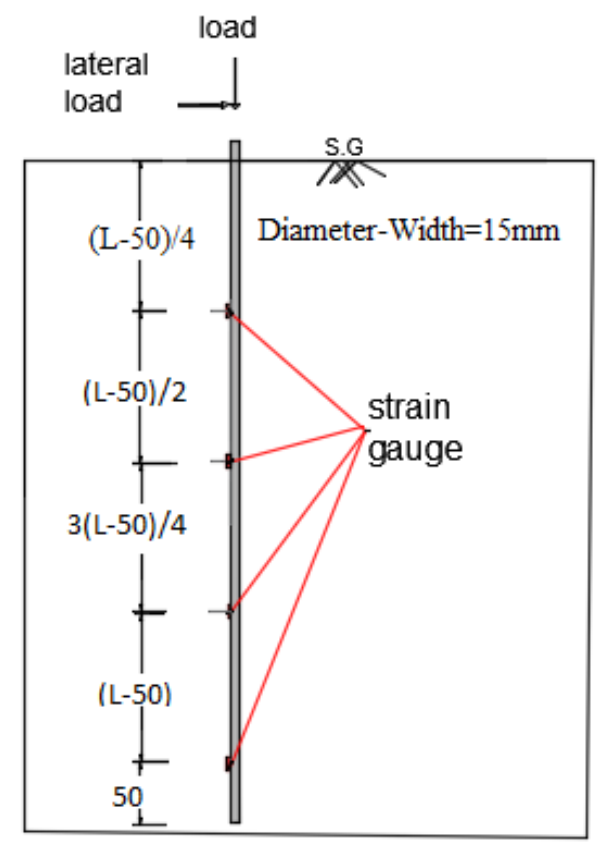

Fig. 3. The position of the strain gauges used in this study.

\subsection{Method of Loading Application}

The lateral load was applied to the pile by a wire which attached by the tip of the pile from one direction and from the other is related to the loading base via a frictionless pulley. The lateral deformation of the pile above the soil surface was measured by two dial gauges above the soil surface that fixed at the pile tip and the lateral deformation along the pile inside the soil was measured by using the strain gauges. The amount of lateral load $(\mathrm{H})$ equal to $20 \%$ of the allowable vertical load ( $\mathrm{V}$ allowable) that applied in five steps started from $(0.2 \mathrm{H}$ to $\mathrm{H})$. The vertical load was applied to the pile with combination of lateral load through six stages $(0 \%, 20 \%, 40 \%, 60 \%, 80 \%$, and $100 \%$ from $\mathrm{V}$ allowable).

\section{Results and Discussions}

\subsection{Results of the pile tip deformation with loads}

Based on the test results, the lateral load is affected by the ratio of (deformation to the pile diameter/side) that shown in the Figure (4) for aluminum and steel piles for both square and circular sections and $\mathrm{L} / \mathrm{D}=25,45$.

Figure (4) shows that the lateral resistance of the steel circular pile was more than that of the aluminum circular pile about (37\%), while in case of square section, the lateral resistance of the steel square pile was more than that of aluminum square pile about $(45 \%)$. For aluminum pile, the lateral resistance of the pile with square shape was more than that of circular shape around (54\%), also, in case of steel pile with square shape, the lateral resistance of it was more than that of circular shape about $(47 \%)$. This result was agreed with Abbas et al. (2008), they showed that the lateral resistance of pile with square section was more than that of circular section.

Figure 5 presents the full behavior of the lateral load with deformations to the diameter/or side ratio relationships for aluminum and steel piles with square sections for all increments of vertical load. 


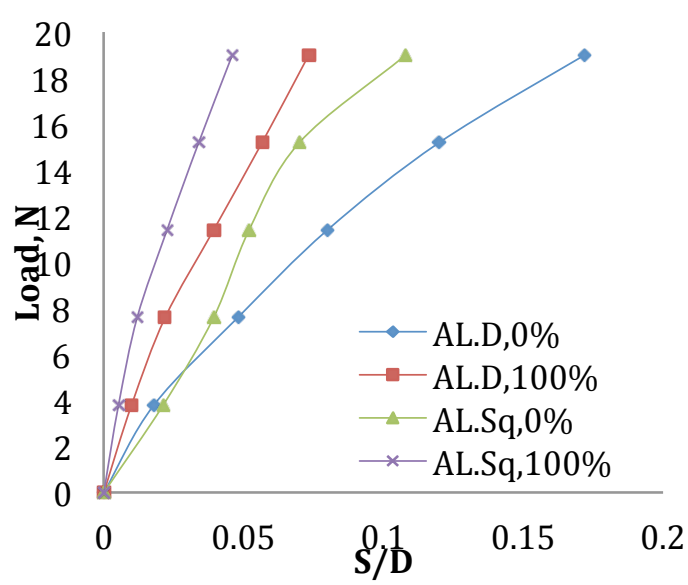

a)

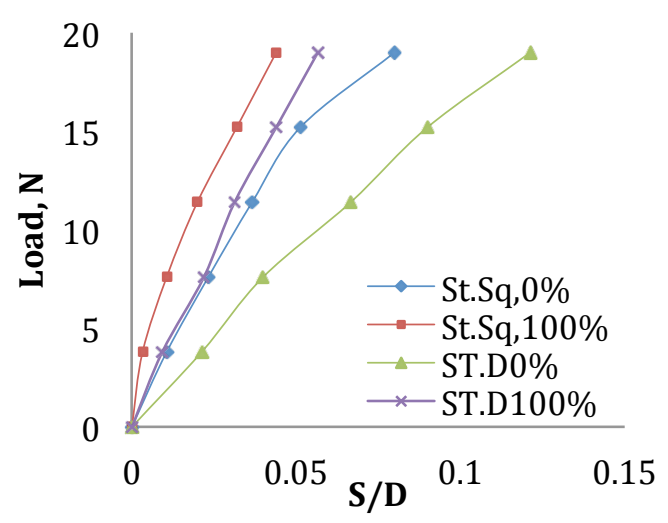

b)

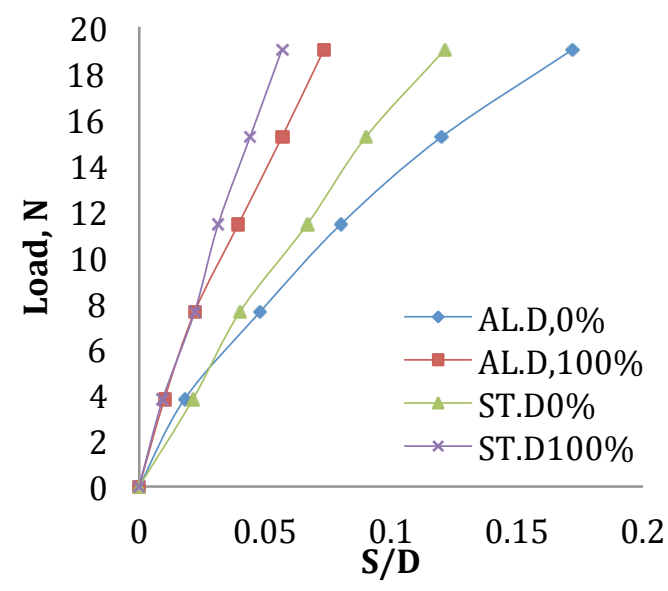

c)

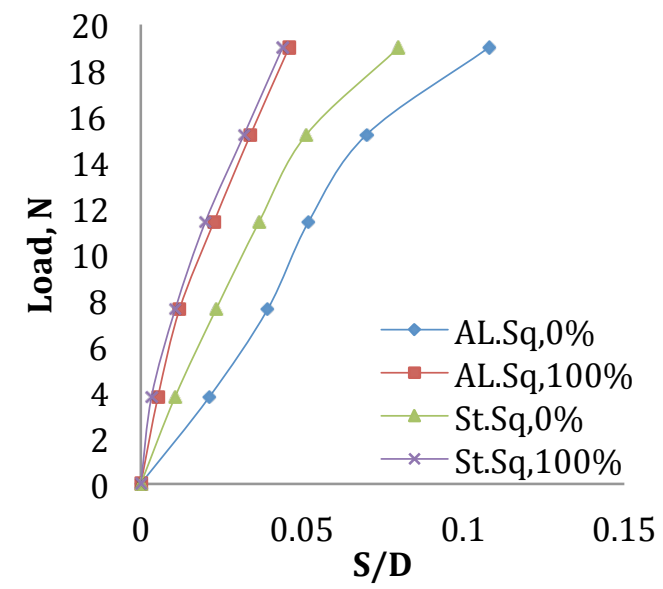

d)

Fig. 4. Lateral load-S/B relationship for aluminum and steel piles with square and circular cross section, L/B or L/D of 25

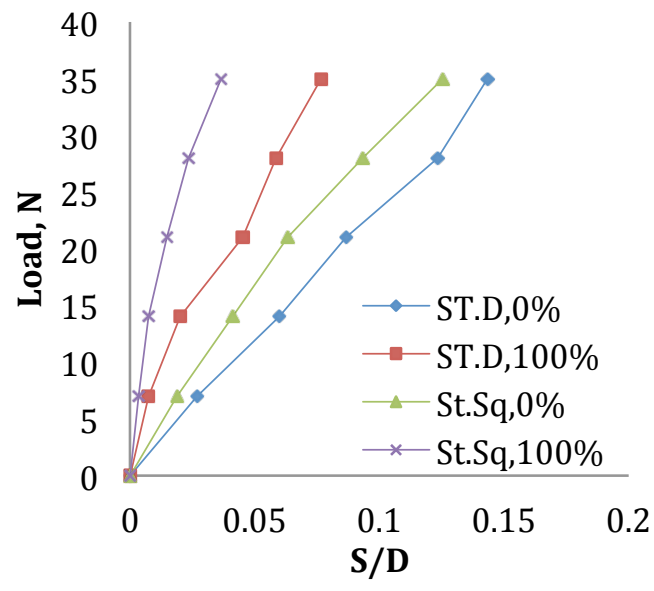

a)

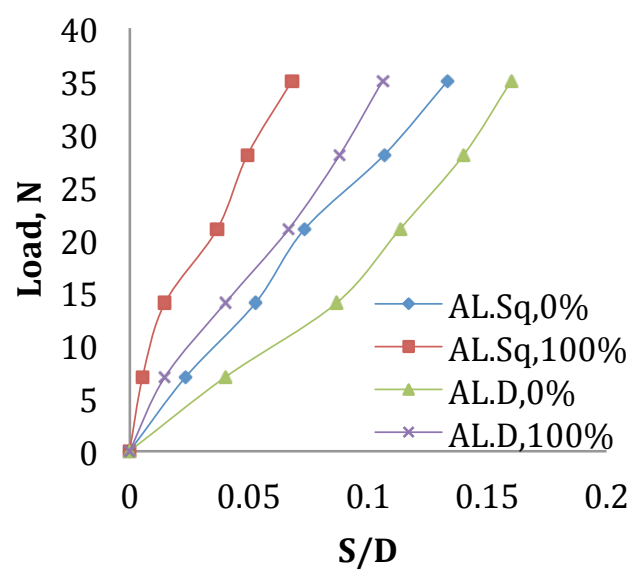

b)

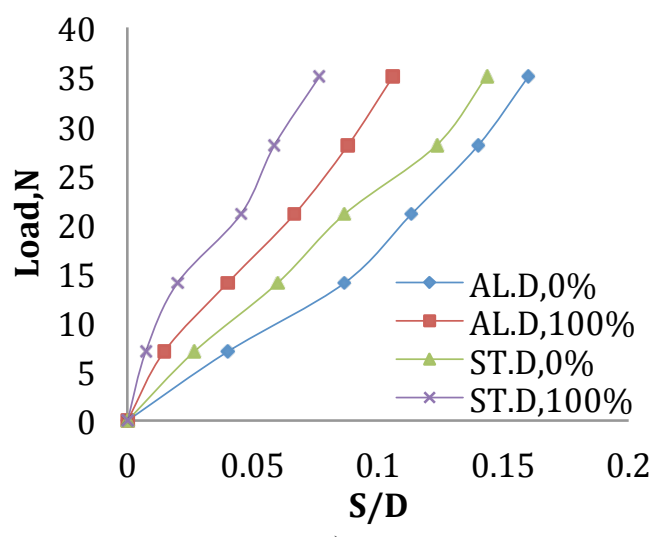

c)

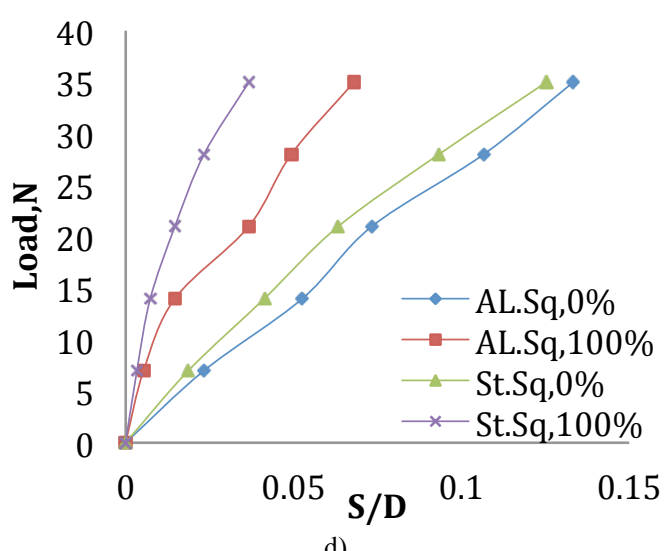

Fig. 5. Lateral load-S/B relationship for aluminum and steel piles with square and circular cross section, $\mathrm{L} / \mathrm{B}$ or $\mathrm{L} / \mathrm{D}$ of 45 
The results are similar to that obtained from Figure 4 with different values. It can be shown that the lateral resistance of steel pile with circular shape was more than that of the aluminum pile about $(27 \%)$. While the lateral resistance of steel pile with square shape was more than that of aluminum pile about $(46 \%)$. The lateral resistance of the square aluminum pile was more than that of aluminum circular pile about (35\%), and the lateral resistance of steel pile with square shape was more than that of a circular shape around $(52 \%)$.

\section{2. Results of Pile deformation with depth}

Figures (6) and (7), shows the effect of axial load on the lateral pile behavior along the depth for $\mathrm{L} / \mathrm{D}=25$ and 45 . It can be concluded that the increase in axial load usually affects the pile response especially at the upper part of the pile because of the upper part deforms more than the other parts in case of long pile. The lower part of the pile was affected also but in little form when the pile carries axial load in addition to lateral load. This is due to increase of lateral soil resistance with a depth that prevents the pile from moving laterally. In general, the presence of axial load led to decrease the deflection of the pile because it leads to increase the pile stiffness. This result was agreed with Karasev, et al. (1977), Karthigeyan, et al. (2006), they showed that the presence of axial load led to decrease the pile deflection.

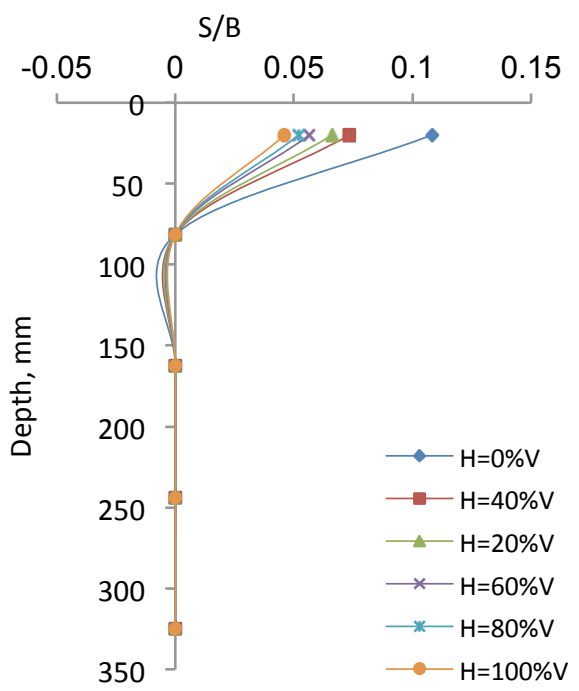

a)

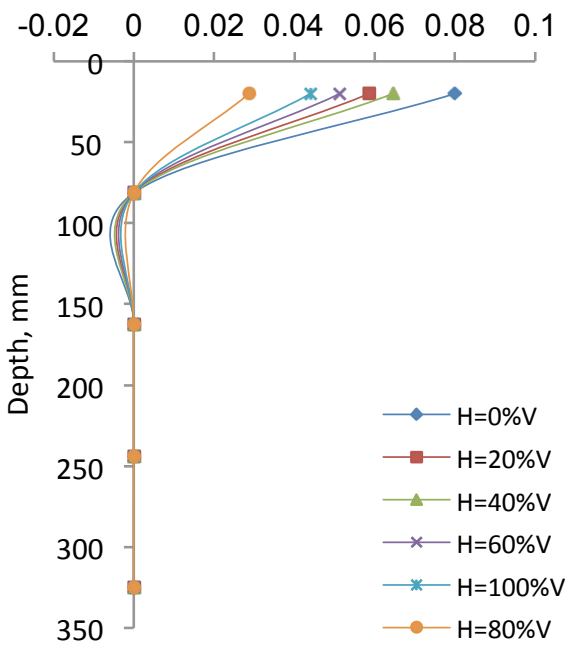

b)

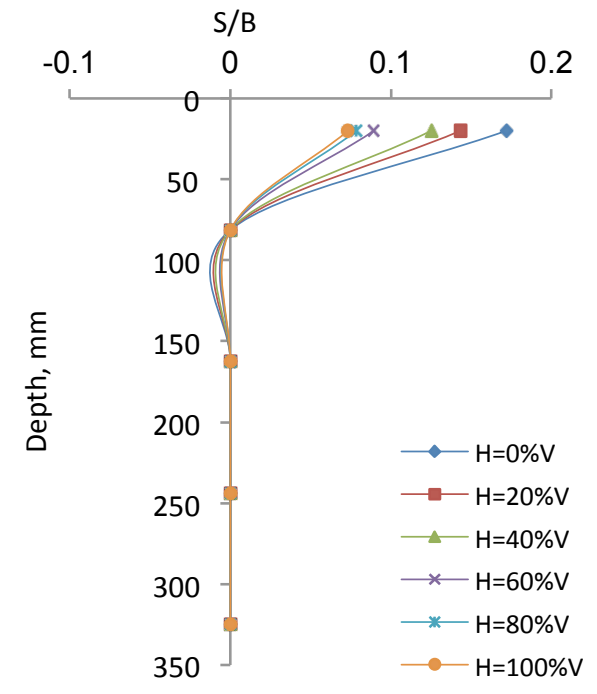

c)

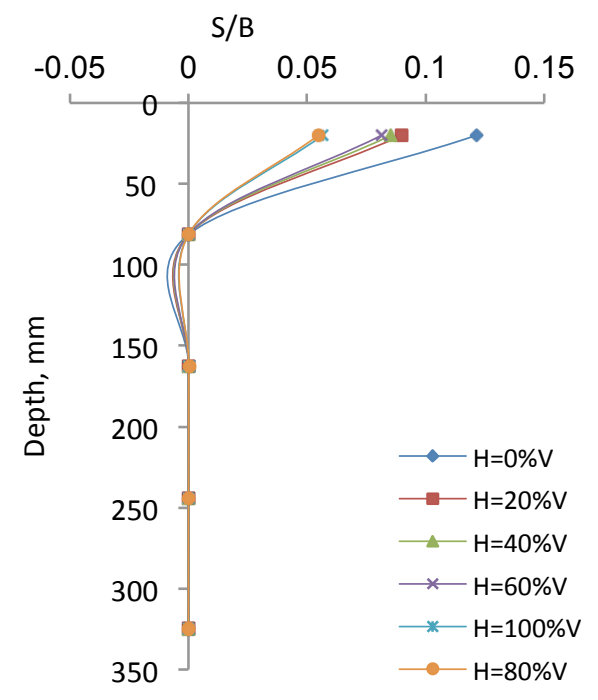

d)

Fig. 6. Lateral pile deformation-depth for $\mathrm{Dr}=70 \%$ : (a) square AL. pile, (b) square ST. pile, (c) circular AL. pile and (d) circular ST. pile

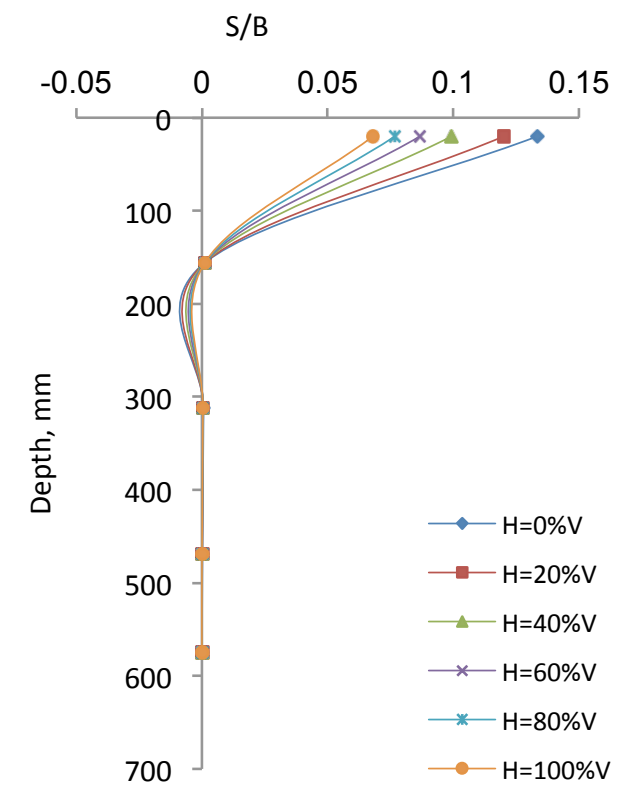

a) 


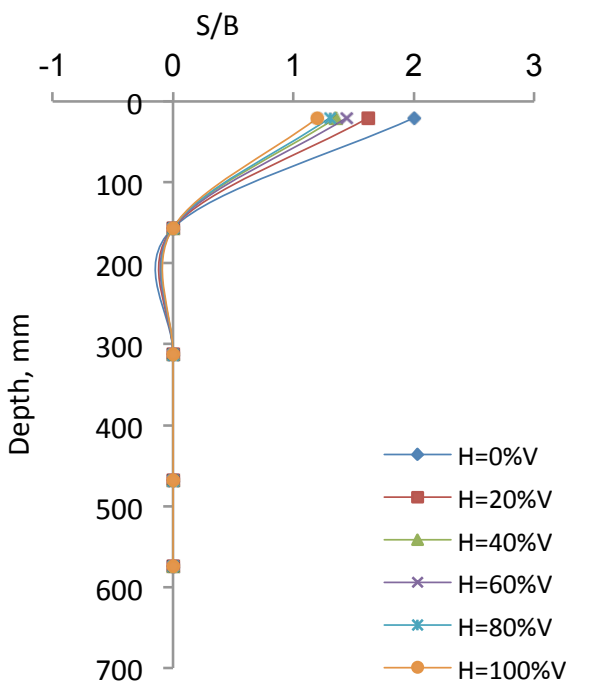

b)

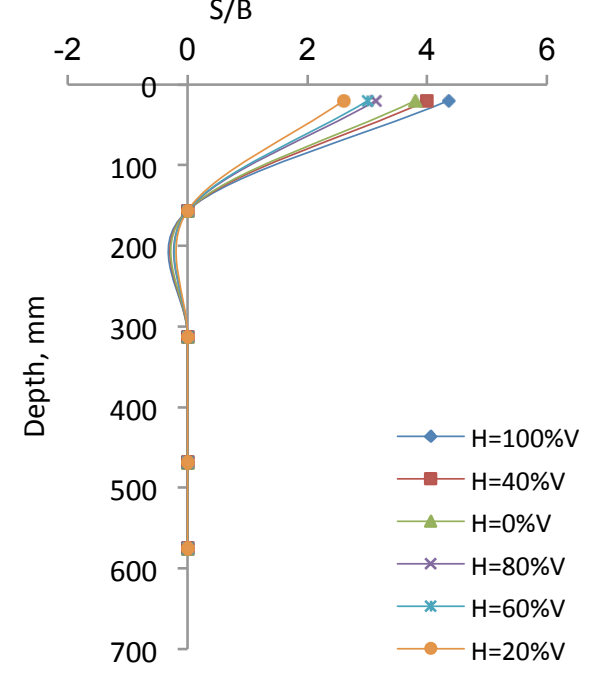

c)

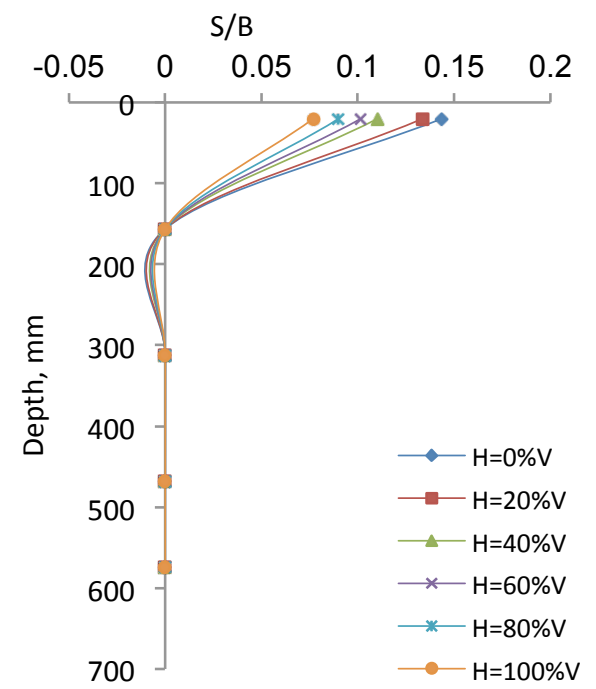

d)

Fig. 7. Lateral pile deformation-depth for $\mathrm{Dr}=70 \%$ : (a) square AL. pile, (b) square ST. pile, (c) circular AL. pile and (d) circular ST. pile

\section{Conclusions}

Based on the test results the following conclusions can be obtained:

1-The increase of vertical load which applied to pile simultaneously with lateral load was effected on the pile response especially at the pile upper part. The presence of axial load lead to decrease the pile deflection.

2-The lateral resistance of square section was more than that of circular section for both cases (steel and aluminum piles), this is due to the large surface area of the square section of the piles.

3-The lateral resistance of steel piles with both square and circular sections was more than that of aluminum piles. This improvement in lateral pile behavior can used in practices when design the deep foundation. The ratio of deformation point, the behavior of soil materials should be analyzed as a nonlinear form in the theoretical researches.

This is an Open Access article distributed under the terms of the Creative Commons Attribution License

\section{(c) (i) (5)}

\section{References}

1. Abbas, J.M., Chik, Z., Taha, M.R. 2017. Lateral pile response subjected to different combination of loadings. Journal of Engineering Science and Technology Review. 10 (6), 195- 202.

2. Abbas, J.M., Chik, Z., Taha, M.R. 2015. Influence of axial load on the lateral pile groups response in cohesionless and cohesive soil. Frontiers of Structural and Civil Engineering. 9 (2), 176-193.

3. Abbas, J.M., Chik, Z., Taha, M.R. and Shafiqu Q. S. M. 2010. Time-dependent lateral response of pile embedded in elasto-plastic soil. Journal of Central South University of Technology 17 (2), 372-380.

4. Abbas, J.M., Chik, Z.Hj., Taha, M.R. 2008. Single pile simulation and analysis subjected to lateral load. Electronic Journal of Geotechnical Engineering 13 (E)

5. Abdrabbo F. M. and Wakil A. Z. 2016. Laterally loaded helical piles in sand. Alexandria Engineering Journal. 55(4):1-7
6. Bouafia A. 2007. Single piles under horizontal loads in sand: determination of $P-Y$ curves from the preboredpressure meter test. Proceedings of the 18th International Conference on Soil Mechanics and Geotechnical Engineering, Paris, France.

7. Fatahi, B., Basack, S., Ryan, P., Zhou, W-H and Khabbaz, H. (2014), Performance of laterally loaded piles considering soil and interface parameters.Geomechanics and Engineering, 7(5), 495-524.

8. Karasev, O. V., Talanov, G. P. and Benda, S. F. (1977), Investigation of the Work of Single Situ-Cast Piles under Different Load Combinations. Soil Mech. Found. Eng., No. 3, 173-177.

9. Karthigeyan, S., Ramakrishna, V. and Rajagopal, K.(2006),Influence of vertical load on the lateral response of piles in sand. Computers and Geotechnics, 33(2), 121131 .

10. Karthigeyan, S., Ramakrishna, V. and Rajagopal, K. (2007), Numerical investigation of the effect of vertical load on the 
lateral response of piles.Journal of Geotechnical and Geoenvironmental Engineering, 133(5), 512-521.

11. Lee, J., Prezzi, M. and Salgado, R. (2011), Experimental investigation of the combined load response of model piles driven in sand. Geotechnical Testing Journal, 34(6), 653667.

12. Ozden, G., and Akdag, C. T. 2009. Lateral load response of steel fiber reinforced concrete model piles in cohesion lesssoil. "Construction and Building Materials 23(2): 785794.

13. Rahman, M. M., Karim, M. R., Baki, A. L. and Paul, D. K., (2009), Ultimate Lateral Load Resistance of Laterally
Loaded Pile. University of Canterbury.Civil and Natural Resources Engineering.

14. RajagopalK. and Karthigeyan S., 2008. Influence of Combined Vertical and Lateral Loading on the Lateral Response of Piles. The 12th International Conference of International Association for Computer Methods and Advances in Geomechanics (IACMAG) 1-6 October.

15. Yan S., Wang Y., Du H., Yu L., and Zheng S., 2016. Evaluation of the Lateral Forces Acting on Stabilizing Piles Considering the Resistance of the Lower Zone of $A$ Landslide in the Three Gorges Reservoir, Chind. Journal of Engineering Science and Technology Review, 9(6):170-177. 